\title{
SILVER SYNDROME: AN INFANT WITH NECROPSY FINDINGS
}

\author{
Kiyoshi ImaIzumI, ${ }^{1}$ Tetsuro OGINo, ${ }^{2}$ and Tadashi KaJII ${ }^{1}$ \\ ${ }^{1}$ Department of Pediatrics and ${ }^{2}$ Second Department of Pathology, Yamaguchi \\ University School of Medicine, Ube, Yamaguchi 755, Japan
}

\section{INTRODUCTION}

The Silver syndrome is characterized by intrauterine growth retardation, small triangular facies, asymmetry and clinodactyly. While more than 100 cases of the syndrome have been reported, no autopsy findings have been described (Silver, 1964). We report here such an instance.

\section{CASE REPORT}

A newborn female infant, born at term to a 29 -year-old mother and a 34 -yearold father: both healthy and unrelated. An elder sister was healthy. The patient, delivered by Cesarian section because of polyhydramnios, weighed $2,200 \mathrm{~g}(-2.2$ $\mathrm{SD})$, measured $43.7 \mathrm{~cm}(-2.8 \mathrm{SD})$, and head circumference $35.3 \mathrm{~cm}(+1.5 \mathrm{SD})$. Feeding difficulties and respiratory distress steadily progressed. She was fed nasally but expired at 32 days of age.

Physical findings. Included extreme asymmetry of the entire body with the left side larger than the right ( $c f$. Fig. 1), while no asymmetry of the head was noted. Disproportionately large head, small triangular facies, frontal bossing, antimongoloid slanting of the palpebral fissures, ptosis of the eyelids, turned-down corners of the mouth, cleft soft palate, low-set asymmetric ears, clinodactyly of the fifth fingers and overlapping of the fourth over the third toes.

Laboratory findings. Neonatal hypoglycemia. A peripheral blood lymphocyte culture and skin fibroblast cultures from both sides of the body all yielded a 46,XX karyotype.

$X$-ray examination. Disproportionately large, symmetric skull with open cranial sutures and small and asymmetric facial cranium. Bone age at 30 days of life: left half correspondent to 6 months and the right half correspondent to a newborn period.

Autopsy findings. Asymmetry of the skeletal bones, spinal cord, arteries, veins,

Received March 3, 1983 


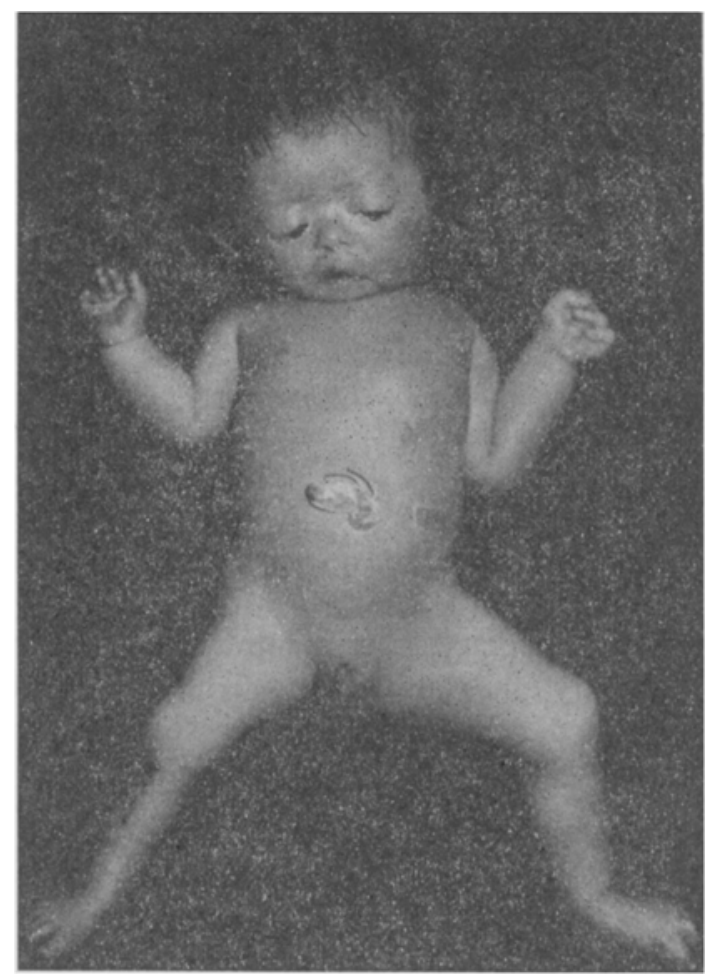

Fig. 1. The patient at autopsy. Asymmetric triangular face with disproportionately large symmetric head, antimongoloid slanting of the palpebral fissures, ptosis of the eyelids, and turned down corners of the mouth, asymmetry of extremities.

tongue, thyroid gland, lungs, liver, kidneys, adrenals, and the uterus. The brain weighed $320 \mathrm{~g}$ (normal $498.2 \pm 7.2 \mathrm{~g}$ ) and was symmetric (Fig. 2).

Microscopic examinations of paired internal organs (brains, thyroid, lungs, liver lobes, kidneys and adrenals) disclosed no appreciable asymmetry in terms of the size of cells and microscopic structures. The mean number of glomeruli in $\mathrm{mm}^{2}$ of the left renal cortex was 13.4, while that in the right cortex was 13.5. The mean diameter of glomeruli $(\mathrm{n}=100)$ in the left renal cortex was $89 \mu \mathrm{m}$, while that in the right was $87.7 \mu \mathrm{m}$. No remarkable histological changes were noted in the cerebrum, cerebellum and the pituitary, thyroid and adrenal glands.

\section{DISCUSSION}

Several reports are available on autopsy findings of patients with congenital hemihypertrophy, a disease similar to, but different from the Silver syndrome. Of the three patients with congenital hemihypertrophy reported with autopsy findings, two (Hutchinson, 1904; Carter, 1953) showed asymmetry of paired internal organs 

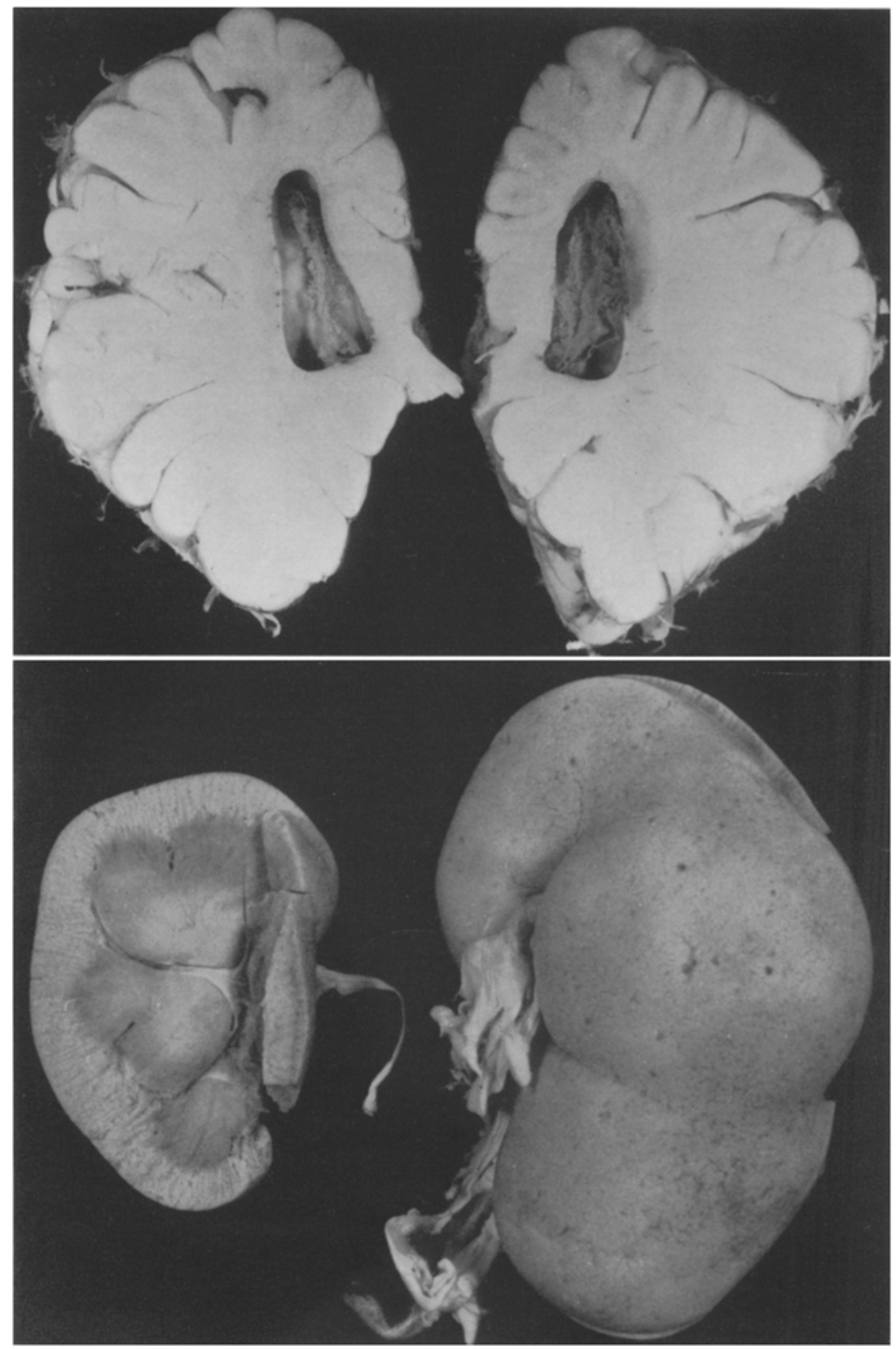

Fig. 2. Upper half: Both cerebral hemispheres, sulci, gyri and ventricles of the cerebri and the cerebelli are symmetric. Lower half: Marked asymmetry between the kidneys. The right kidney measured $4 \mathrm{~cm} \times 2.3 \mathrm{~cm} \times 1.2 \mathrm{~cm}$ and weighed $7.4 \mathrm{~g}$, while the left kidney measured $2.7 \mathrm{~cm} \times 1.4 \mathrm{~cm} \times 1.0 \mathrm{~cm}$ and weighed $2.8 \mathrm{~g}$.

Vol. 28, No. 3, 1983 
while one (Ward and Henry, 1947) did not. None of the three patients had asymmetry of the brains. It seems that the brain is not involved in asymmetric development in both congenital hemihypertrophy and the Silver syndrome. The absence of asymmetry of cells and microscopic structures in paired internal organs of our patient suggests that there was a difference in the number of cells between paired organs at the beginning of organogenesis. We do not have a ready explanation why the brain in our patient escaped asymmetry.

\section{REFERENCES}

Carter, F.S. 1953. A case of congenital hemihypertrophy showing variations in bone age and development. Arch. Dis. Child. 28: 321-324.

Hutchinsons, R. 1904. A case of hemi-hypertrophy in which the internal organs were affected. Brit. J. Child. Dis. 1: 258-260.

Silver, H.K. 1964. Asymmetry, short stature, and variations in sexual development: A syndrome of congenital malformations. Am. J. Dis. Child. 107: 495-515.

Ward, J., and Henry, H.L. 1947. A review of the subject of congenital hemihypertrophy and a complete case report. J. Pediat. 31: 403-414. 